\title{
Capturing context and mental state of knowledge workers
}

\author{
Saskia Koldijk \\ Radboud University Nijmegen \& TNO \\ s.koldijk@cs.ru.nl
}

Supervisors: Wessel Kraaij and Mark Neerincx

\section{MOTIVATION}

We live in an information society, in which effective and efficient interaction with information is crucial. Many people are knowledge workers, whose main job it is to interpret and generate information. Due to their typical working conditions these people often experience stress while working with information [1]. They get overwhelmed by all the available information and often have a fragmented way of working due to inappropriate interruptions, for example by incoming mails with information requests. As a consequence, this way of working can diminish well-being at work, which -for some people- may finally result in burn-out.

We aim to develop a tool that supports knowledge workers during their work. The final aim is to increase well-being at work. Therefore, the tool should be perfectly adapted to the user's current context and user state to provide appropriate feedback and support for their work. Feedback can create more awareness of e.g. mental workload or stress, and possible underlying causes. By providing support, e.g. presenting useful information just in time, the mental workload and stress can be kept in optimal ranges, ensuring well-being at work. Our three main research topics are:

- Requirements for the tool: which aspects need to be considered for making an effective support tool?

- Automatic recognition of context and user state: how can we enable inference of relevant aspects of context and user state, based on unobtrusive sensing?

- Developing feedback and support: which methods of feedback and support are most effective for the user?

\section{METHODOLOGY TO BE USED}

Data from unobtrusive sensors will be interpreted by means of pattern recognition approaches and the recognized information will then be used to base feedback and support upon, which is optimally adapted. The performance of our algorithms for context and user state recognition and the final tool will be evaluated in real-world office settings, as well as its effects on well-being at work. Advancements in the state of the art will be achieved in the areas of multimodal sensor integration, contextual reasoning, activity and task recognition, mental and physical state estimation and user adaptation through learning.

Permission to make digital or hard copies of all or part of this work for personal or classroom use is granted without fee provided that copies are not made or distributed for profit or commercial advantage and that copies bear this notice and the full citation on the first page. To copy otherwise, or republish, to post on servers or to redistribute to lists, requires prior specific permission and/or a fee.

IIIX'12 Nijmegen, The Netherlands.

Copyright 2012 ACM 978-1-4503-1282-0/2012/08 ... \$15.00.

\section{INITIAL RESULTS \& PLANNED WORK}

Requirements for the tool were collected by means of a questionnaire and a workshop. Results show that users value automatic interpretation of low level data and personalization and privacy play an important role.

Regarding automatic recognition of context and user state first steps enabling automatic task recognition were already taken [2]. Computer interaction data of knowledge workers was collected, together with annotations. We found that simple classifiers (Nearest Neighbour, Decision Tree, Bayesian Network, Neural Network) learn to recognize 12 different tasks with an accuracy of up to $80 \%$ after only 2.5 hours (30 instances) of real-world training data, which is very promising. As next step we will work on the automatic recognition of other aspects, like e.g. the content the user is involved in or his mental workload. We created an initial model to link various sensors to these different aspects of the user's context and mental state [3]. In an experiment we will collect more data and investigate the recognition accuracy that can be reached, as well as the usefulness of various sensors and features.

Regarding feedback and support, we already collected some ideas in a workshop with knowledge workers. Results show that users like feedback which gives them an overview in one glance, with plots for more detail when desired. Regarding support, several ideas were offered, from email blocking to getting points for not switching between tasks. In the future these ideas will be worked out in more detail and tested for their appropriateness.

\section{ACKNOWLEDGMENTS}

This publication was supported by the Dutch national program COMMIT (project P7 SWELL ${ }^{1}$ ).

\section{REFERENCES}

[1] Michie, S. (2002). Causes and management of stress at work. Occupational and Environmental Medicine, 59, 67-72.

[2] Koldijk, S., van Staalduinen, M., Neerincx, M., Kraaij, W. (2012). Real-time task recognition based on knowledge workers' computer activities. Proceedings of ECCE 2012 (Edinburgh, Scotland, 28-31 August 2012).

[3] Koldijk, S., Neerincx, M., Kraaij, W. (2012). Unobtrusively measuring stress and workload of knowledge workers. Proceedings of Measuring Behavior (Utrecht, The Netherlands, 28-31 August 2012)

\footnotetext{
${ }^{1}$ http://www.commit-nl.nl > Smart reasoning systems for wellbeing at work and at home (SWELL)
} 